Case Report

\title{
A Case of Cushing's Syndrome due to Ectopic Adrenocorticotropic Hormone Secretion from Esthesioneuroblastoma with Long Term Follow-Up after Resection
}

\author{
Leslee N. Matheny $\mathbb{D}^{1},{ }^{1}$ Sudipa Sarkar, ${ }^{2}$ Hanyuan Shi $\mathbb{D}^{3},{ }^{3}$ Jiun-Ruey Hu, ${ }^{4}$ Hannah Harmsen, ${ }^{5}$ \\ Ty W. Abel, ${ }^{5}$ Shubhada M. Jagasia, ${ }^{1}$ and Shichun Bao (1) ${ }^{1}$ \\ ${ }^{1}$ Vanderbilt University Medical Center, Division of Endocrinology, Department of Medicine, Vanderbilt University, \\ 1215 21st Avenue South, Nashville, TN 37232, USA \\ ${ }^{2}$ Johns Hopkins University School of Medicine, Division of Endocrinology, Diabetes and Metabolism, 5501 Hopkins Bayview Circle, \\ Baltimore, MD 21224, USA \\ ${ }^{3}$ Vanderbilt University Medical Center, Department of Surgery, Vanderbilt University, 1161 21st Avenue South, Nashville, \\ TN 37232, USA \\ ${ }^{4}$ Vanderbilt University School of Medicine, 2215 Garland Ave, Nashville, TN 37232, USA \\ ${ }^{5}$ Vanderbilt University Medical Center, Department of Pathology, Microbiology and Immunology, 1161 21st Avenue South, \\ Nashville, TN 37232, USA
}

Correspondence should be addressed to Shichun Bao; shichun.bao@vanderbilt.edu

Received 6 September 2017; Accepted 20 December 2017; Published 4 February 2018

Academic Editor: Eli Hershkovitz

Copyright ( 92018 Leslee N. Matheny et al. This is an open access article distributed under the Creative Commons Attribution License, which permits unrestricted use, distribution, and reproduction in any medium, provided the original work is properly cited.

\begin{abstract}
We present a case of a 52-year-old male who developed Cushing's Syndrome due to ectopic adrenocorticotrophic hormone (ACTH) secretion from a large esthesioneuroblastoma (ENB) of the nasal sinuses. The patient initially presented with polyuria, polydipsia, weakness, and confusion. Computed tomography scan of the head and magnetic resonance imaging showed a $7 \mathrm{~cm}$ skull base mass centered in the right cribriform plate without sella involvement. Work-up revealed ACTH-dependent hypercortisolemia, which did not suppress appropriately after high-dose dexamethasone. Subsequent imaging of the chest, abdomen, and pelvis did not reveal other possible ectopic sources of ACTH secretion besides the ENB. His hospital course was complicated by severe hypokalemia and hyperglycemia before successful surgical resection of the tumor, the biopsy of which showed ENB. Postoperatively, his ACTH level dropped below the limit of detection. In the ensuing 4 months, he underwent adjuvant chemoradiation with carboplatin and docetaxel with good response and resolution of hypokalemia and hyperglycemia, with no sign of recurrence as of 30 months postoperatively. His endogenous cortisol production is rising but has not completely recovered.
\end{abstract}

\section{Introduction}

Esthesioneuroblastoma (ENB), or olfactory neuroblastoma, is a tumor of the nasal and paranasal sinuses, derived from the olfactory neuroepithelium $[1,2]$ and represents only $3-6 \%$ of all cancers in the nasal cavity and paranasal sinuses [2,3]. Paraneoplastic ENB is rare and only has been reported in a handful of cases in the literature. One type of paraneoplastic ENB is ectopic adrenocorticotrophic hormone (ACTH) secretion. Ectopic ACTH secretion in ENB is highly unusual and can lead to severe symptoms of Cushing's Syndrome (CS) including persistent hypertension, hypokalemia, hyperglycemia, and opportunistic infections. It is important to be cognizant and recognize the pathophysiology, work-up, and treatment of ACTH-secreting ENB in its varied presentations. We present a case here for that discussion. 

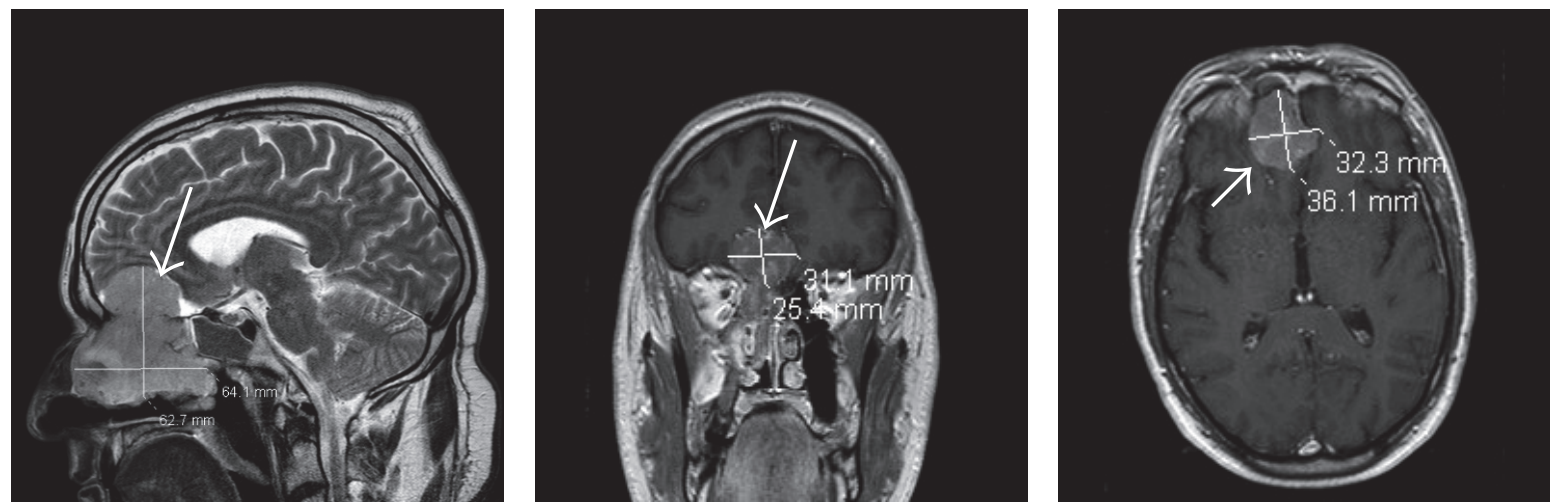

(a) Magnetic resonance imaging scan of the head with contrast, T1, sagittal, coronal, and axial views. These demonstrate a $7.5 \times 4.1 \times 3.4 \mathrm{~cm}$ skull base mass in the right cribriform plate (white arrow)
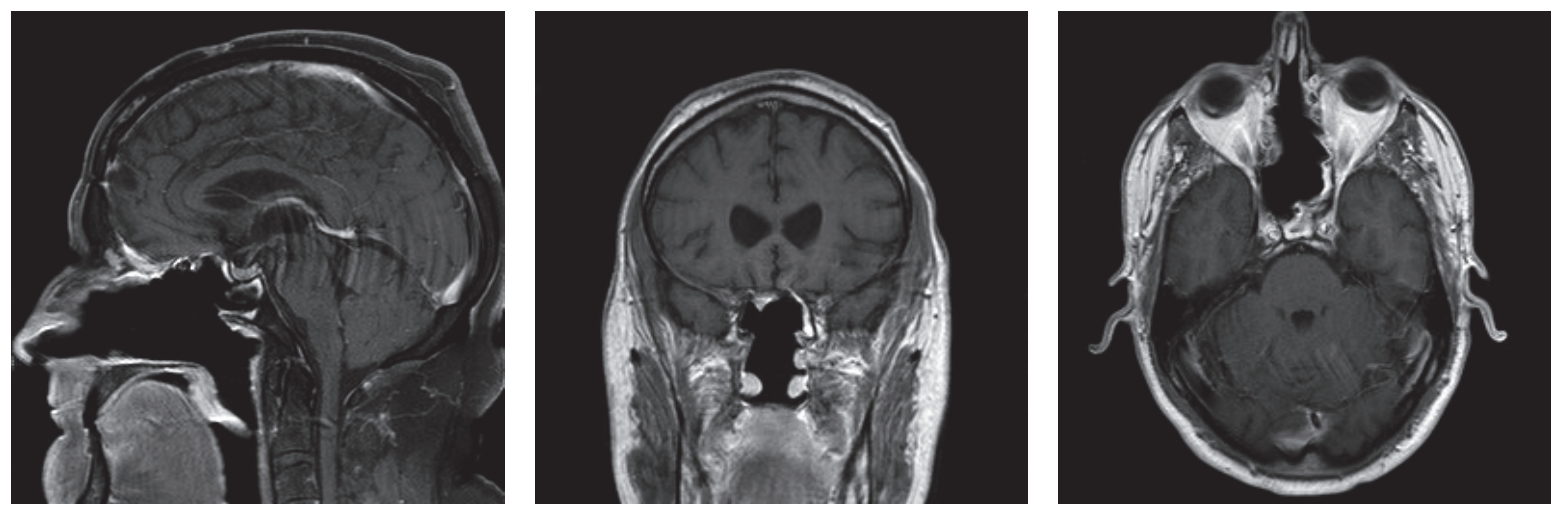

(b) Twenty-eight months later, magnetic resonance imaging scan of the head with contrast and T1 view showing posttreatment changes in anterior cranial fossa with no appreciable change in appearance of dural thickening along cribriform plate and anterior cranial fossa. There is some encephalomalacia and bilateral frontal lobes are unchanged from previous scans

FIGURE 1

\section{Case Presentation}

A 52-year-old Caucasian male with a past medical history of hypertension presented to our hospital for planned resection of a large skull base mass of the right cribriform plate by the neurosurgery service. He had initially presented at an outside hospital with anosmia and right nasal airway obstruction. He was diagnosed with new onset diabetes mellitus. Computed tomography (CT) scan of the head and magnetic resonance imaging $(\mathrm{MRI})$ of the face revealed a $7.5 \times 4.1 \times 3.4 \mathrm{~cm}$ mass of the right cribriform plate, extending intracranially into the right anterior cranial fossa and displacing the frontal lobe with no sellar involvement. Imaging at our center confirmed the findings (Figure 1(a)). However, on the planned day of procedure, his labs were significant for severe hypokalemia with a potassium of $2.0 \mathrm{mmol} / \mathrm{L}$ (normal range: 3.3-4.8) and metabolic alkalosis with arterial $\mathrm{pH}$ of 7.64 (7.35-7.45) and serum $\mathrm{HCO}_{3}{ }^{-}$of $44 \mathrm{mmol} / \mathrm{L}$ (21-29). Surgery was postponed, and the endocrinology service was consulted. It was noted that the patient had been experiencing several weeks of severe weakness, polyuria, and more than 20 pounds of weight loss before the scheduled operation. He was initially treated with oral and intravenous potassium chloride $(\mathrm{KCl})$, but his serum potassium continued to be refractory to acute repletion. In addition, he had increased insulin requirement to control his serum glucose levels.

As part of his hypokalemia work-up, he was found to have a significantly elevated random plasma cortisol of $1851 \mathrm{nmol} / \mathrm{L}$ and plasma ACTH of $152 \mathrm{pmol} / \mathrm{L}$ (1.5-11.2). 24-hour urine free cortisol was also grossly elevated at $32,027 \mathrm{nmol} /$ day $(<165)$. His renin and aldosterone levels were normal. His TSH was also normal. Thus, CS was suspected, and imaging was ordered to locate possible sources. CT scan of his chest, abdomen, and pelvis noted bilateral adrenal enlargement, but no distinct nodules and no apparent sources of ACTH secretion were found. This raised the possibility of ENB being the ectopic source. High-dose (8 mg) dexamethasone suppression testing was performed, with the next-day morning cortisol of $1895 \mathrm{nmol} / \mathrm{L}$, which was not suppressed at all, and ACTH was still elevated at $75.7 \mathrm{pmol} / \mathrm{L}$. $\mathrm{He}$ continued to be aggressively treated with $\mathrm{KCl}$. Eplerenone, magnesium oxide, and ketoconazole were also added. On day 5 , his potassium was stabilized in the low-normal range. He was discharged on day 6 , with a plan for a definitive resection of the tumor in 3 weeks, after the Christmas and New Year holidays.

However, the patient was readmitted 3 days later, for confusion, hypotension, and continued hypokalemia 


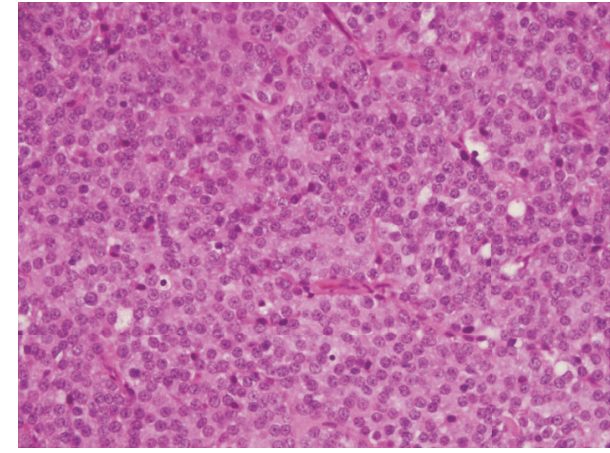

(a) The skull base tumor, measuring $3.5 \times 3.0 \times$ $2.0 \mathrm{~cm}$ in aggregate. On hematoxylin and eosin $(\mathrm{H} \& \mathrm{E})$ staining, the tumor is composed of small, round uniform cells with stippled chromatin and distinct but inconspicuous nucleoli, growing in a diffuse and lobular pattern within a neurofibrillary matrix

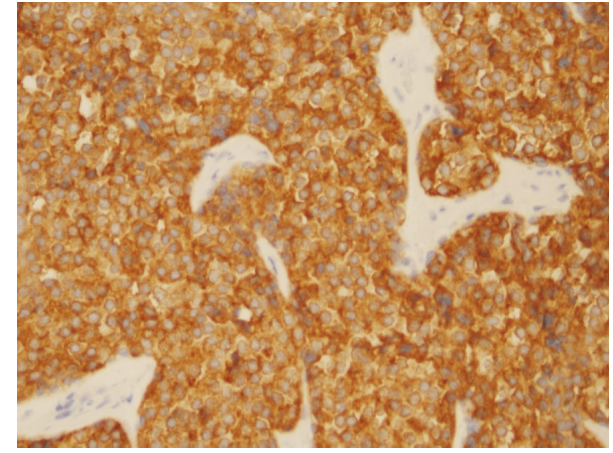

(b) An immunohistochemical stain against synaptophysin, a neuroendocrine marker, shows diffuse, strong cytoplasmic positivity within tumor cells, confirming the neuroendocrine nature of this esthesioneuroblastoma

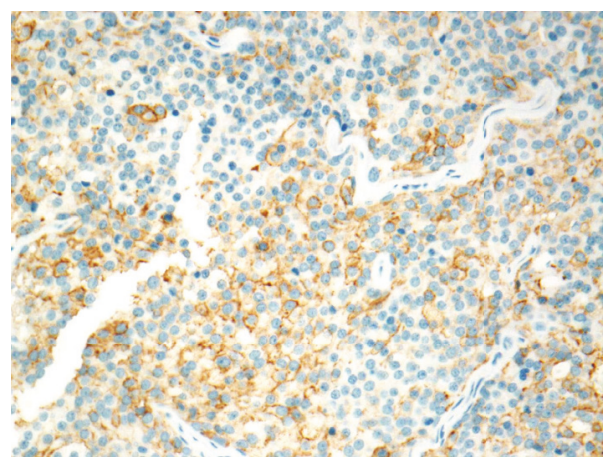

(c) Immunochemistry shows patchy expression of ACTH in the tumor cells (original magnification 400x)

Figure 2: Histology staining of tumor.

refractory to his oral potassium medications. He was once again aggressively potassium repleted, and surgery was performed a week later. A bifrontal craniotomy was performed by the neurosurgery team and bilateral maxillary antrostomy, ethmoidectomy, and sphenoidotomy were performed by otolaryngology along with resection of the tumor under endoscopic guidance. The mass was revealed to be a mixedconsistency lesion eroding through the anterior right planum extending through the dura. Intraoperative biopsy showed that the tumor contained lobular growth of small round cells with uniform hyperchromatic chromatin, inconspicuous nucleoli, and scant fibrillary cytoplasm, with rare mitotic figures present (Figure 2(a)). The cells stained positive for chromogranin, synaptophysin, and CD56 on histology, with S100 highlighting the periphery of the clusters (Figure 2(b)). Final confirmation was done with ACTH-staining, which was positive in the tumor cells (Figure 2(c)). The superior septum and anterior inferior septum were involved by tumor, but the tumor was not present on deeper permanent sections.

The postoperative course was uncomplicated, with decreasing daily potassium and insulin requirements and resolution of metabolic alkalosis (Table 1). He no longer required ketoconazole or eplerenone but needed glucocorticoid for central adrenal insufficiency as ACTH dropped to undetectable level at $<1 \mathrm{pmol} / \mathrm{L}$ the day after surgery (Table 2). Shortly after, the patient underwent adjuvant chemotherapy with carboplatin and docetaxel as well as intensity-modulated radiation therapy for 7 weeks. He was treated on maintenance doses of dexamethasone $0.5 \mathrm{mg}$ daily and then $0.25 \mathrm{mg}$ daily and eventually tapered down to hydrocortisone $15 \mathrm{mg}$ daily for his adrenal insufficiency. He was tapered off insulin 3 months after surgery, with good diabetes control on metformin $500 \mathrm{mg}$ twice daily alone. He was determined to be in complete remission as of his most recent visit to medical oncology, and MRI scans of the brain and face have been negative for recurrence 28 months after the initial resection (Figure 1(b)). Although his hypokalemia has resolved, his endogenous cortisol production is improving but has not yet recovered completely (Figure 3). ACTH stimulation tests revealed that stimulated cortisol at 60 minutes was $52.4 \mathrm{nmol} / \mathrm{L}$ at 3 months, $209.7 \mathrm{nmol} / \mathrm{L}$ at 9 months, $234.5 \mathrm{nmol} / \mathrm{L}$ at 12 months, $231.7 \mathrm{nmol} / \mathrm{L}$ at 16 months, and $364.1 \mathrm{nmol} / \mathrm{L}$ at 26 months, with normal cut-off being greater than $500 \mathrm{nmol} / \mathrm{L}$. 
TABLE 1: Hospital course.

\begin{tabular}{|c|c|c|c|c|c|c|c|c|c|c|c|}
\hline Laboratory & Day & 1 & 2 & 3 & 4 & 5 & $6^{*}$ & $9^{* *}$ & $10-17$ & $18^{\mathfrak{S}}$ & $19-26^{\S \S}$ \\
\hline $\mathrm{K}+(\mathrm{mmol} / \mathrm{L})$ & & 2.0 & 1.9 & 2.2 & 2.8 & 3.4 & 3.6 & 2.3 & $2.5-3.7$ & 3.2 & 3.1 \\
\hline $\mathrm{HCO} 3-(\mathrm{mmol} / \mathrm{L})$ & & 44 & 38 & 39 & 32 & 29 & 35 & 35 & $21-29$ & 31 & 27 \\
\hline $\mathrm{pH}$ & & 7.64 & & & & & & & & 7.56 & 7.55 \\
\hline \multicolumn{12}{|l|}{ Treatments } \\
\hline $\mathrm{KCl}(\mathrm{mEq})$ & & 100 & 200 & 260 & 280 & 200 & 80 & 120 & $(258)$ & 810 & (135) \\
\hline Insulin (Units) & & 68 & 111 & 124 & 131 & 153 & 148 & 138 & (115) & 180 & $(54)$ \\
\hline Eplerenone (mg) & & & 25 & 75 & 125 & 150 & 50 & & & & \\
\hline Ketoconazole (mg) & & & & & & 200 & 200 & & $(350)$ & & \\
\hline Dexamethasone (mg) & & & & & & & & & & 8 & $(0.9)$ \\
\hline
\end{tabular}

${ }^{*}$ Patient discharged on day 6 with eplerenone $25 \mathrm{mg}$ twice a day, ketoconazole $200 \mathrm{mg}$ twice a day, $\mathrm{KCl} 40 \mathrm{mEq}$ four times a day, Lantus 50 units daily, and Lispro 28 units three times a day with meals plus sliding scale. ${ }^{* *}$ Patient readmitted. ${ }^{\S}$ Surgical operation (in italic font). ${ }^{\$}$ Patient discharged on day 26 , postoperative day 8 on dexamethasone $0.5 \mathrm{mg}$ daily, Lantus 20 units daily, and Lispro 10 units three times a day with meals plus sliding scale. The numbers in parentheses represent the average amount per day over time interval.

TABLE 2: Hormonal changes.

\begin{tabular}{|c|c|c|c|c|c|c|c|c|c|c|c|c|c|}
\hline Hormone & Day & 2 & 5 & 9 & $19^{*}-26$ & 57 & 120 & 214 & 302 & 382 & 495 & 713 & 810 \\
\hline Cort-S (60 min) & & & & & & 30 & 215 & 243 & 210 & 276 & 235 & 232 & 364 \\
\hline Cort-S (30 min) & & & & & & 22 & 179 & 229 & 168 & 235 & 204 & 212 & 312 \\
\hline Random cortisol & & 1846 & 1895 & 1868 & & 52 & 141 & 168 & 25 & 160 & 149 & 124 & 141 \\
\hline $\begin{array}{l}\text { Plasma ACTH } \\
(0-13 \mathrm{pmol} / \mathrm{L})\end{array}$ & & 128 & 76 & & $<1$ & $<1$ & 5 & 4 & 1 & 3 & 6 & 6 & 6 \\
\hline
\end{tabular}

\section{Treatments (per}

day)

Hydrocortisone Dexamethasone

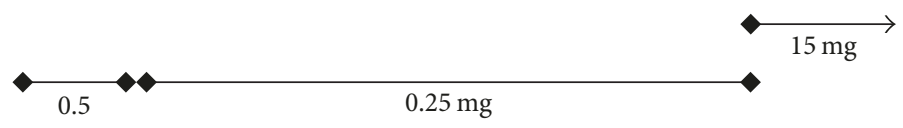

${ }^{*}$ Day 19 was postoperative day 1; patient was discharged on day 26. Cort-S = cortisol levels during ACTH stimulation test. Normal stimulated cortisol levels should be $>500 \mathrm{nmol} / \mathrm{L}$ when measured $60 \mathrm{~min}$ after intravenous administration of $0.25 \mathrm{mg} \mathrm{ACTH}$.

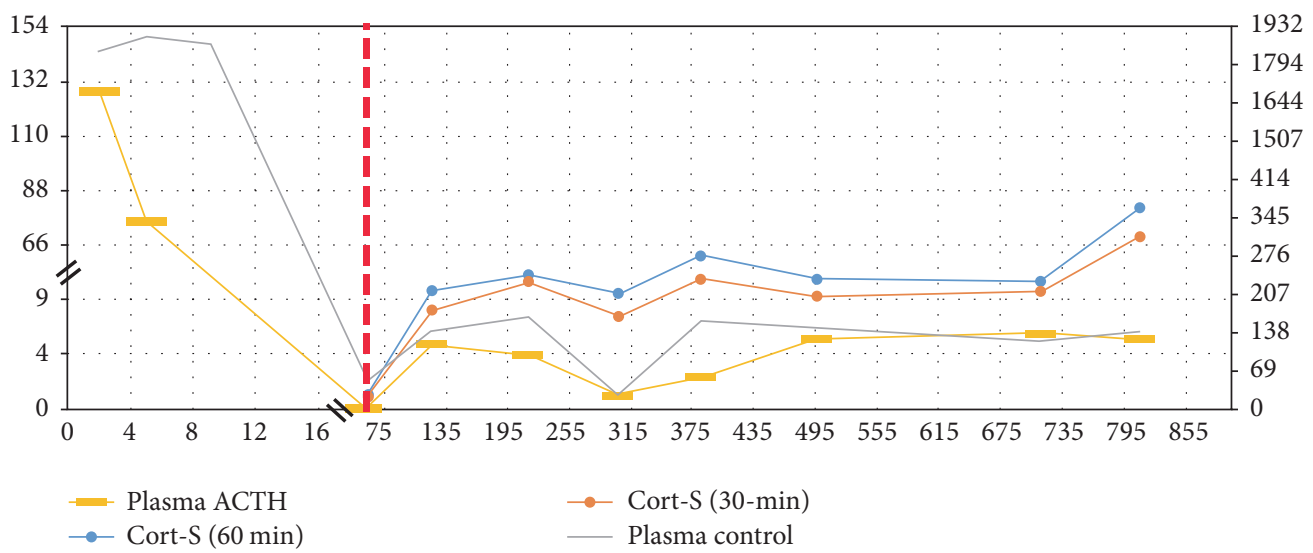

FIGURE 3: Cortisol and ACTH changes before and after operation. The $x$-axis details the day since initial admission to our hospital. Day 19 or the red line is the resection of the esthesioneuroblastoma. The left $y$-axis is the level of plasma adrenocorticotropic hormone (ACTH $(\mathrm{pmol} / \mathrm{L}))$; the right $y$-axis is the level of plasma cortisol (Cort-S $(\mathrm{nmol} / \mathrm{L})$ ). At his outpatient follow-up, $0.25 \mathrm{mg}$ ACTH stimulation tests were done in clinic with assessment of endogenous cortisol production (plasma cortisol level measured at baseline and 30 and 60 minutes after ACTH stimulation). 


\section{Discussion}

This patient was diagnosed with ectopic ACTH syndrome (EAS) based on the preoperative findings of high plasma ACTH concentration, random serum cortisol, and 24-hour urinary cortisol. Other ectopic sources were ruled out by CT scan. At this point, it was strongly suggested that the ENB (Kadish stage B involving two paranasal sinuses) was the source of the ectopic ACTH [4]. Based on these findings and his deteriorating condition, he was emergently taken for resection of the ENB. Pathology of the tumor confirmed synaptophysin positivity on stain, which indicated this was indeed a neuroendocrine neoplasm [5]. This was further confirmed by positive ACTH-staining. Along with the clinical, histological findings and the subsequent improvement in his condition after resection, we confirmed the diagnosis of ectopic ACTH-secreting esthesioneuroblastoma. During his postoperative course, his potassium requirements significantly decreased and he no longer required medication for potassium repletion. Thirty months after resection, the patient still suffers from secondary adrenal insufficiency, but his endogenous cortisol production is improving. He has had no tumor recurrence based on the last surveillance.

Our report demonstrates an unusual presentation of CS due to ectopic ACTH secretion from ENB and adds key data to the literature concerning this rare condition. There are fewer than 25 cases in the literature. We describe an EAS-ENB with comprehensive follow-up up to 30 months after resection, which is one of the longest follow-up periods among studies to date $[6,7]$. Our extensive reporting of the initial hospital course and measurements of hypocortisolism after resection has not previously been described.

Our patient required multiple medication dosage adjustments in order to manage his hypokalemia, including oral and intravenous $\mathrm{KCl}$ and magnesium, as well as antimineralocorticoid such as eplerenone and steroidogenesis inhibitors such as ketoconazole. These were titrated to give him low-normal potassium levels and to relieve symptoms of muscle weakness and numbness. Other case reports have described usage of metyrapone, etomidate, mitotane, and mifepristone as steroidogenesis inhibitors [8]. As described in our report, this was not enough and he was readmitted to the hospital with severe weakness from electrolyte derangements and altered mental status, where definitive treatment per surgery was emergently performed. In addition, we also saw a significant increase in the patient's insulin requirements that eventually decreased to preadmission units after tumor resection.

The patient was placed on different corticosteroid (dexamethasone and later hydrocortisone) for central adrenal insufficiency the months after tumor resection. Baseline ACTH and cortisol levels remained to be low-normal in our patient. He failed all his ACTH stimulation tests so far (cortisol level $<500 \mathrm{nmol} / \mathrm{L} 60 \mathrm{~min}$ after $0.25 \mathrm{mg} \mathrm{ACTH}$ stimulation) but has had improvement of stimulated cortisol. The patient does not have clinical symptoms of adrenal insufficiency such as weight loss, cardiovascular collapse, and hypoglycemia. The chronic massive production of ectopic ACTH from EAS has suppressed his endogenous long term cortisol production (over 30 months). Central adrenal insufficiency usually only requires glucocorticoid replacement, not mineralocorticoid, with hydrocortisone preferred as the most physiological option [9].

In conclusion, we report a case of olfactory neuroblastoma with ectopic ACTH secretion that was treated with resection and adjuvant chemoradiation. Given the paucity of this diagnosis, little is known about how best to treat these patients and how best to screen for complications such as adrenal insufficiency and follow-up. Our case adds more data for better understanding of this disease.

\section{Conflicts of Interest}

The authors declare that there are no conflicts of interest regarding the publication of this paper.

\section{Acknowledgments}

The authors would like to thank the entire hospital team for their care for this patient and those who continue to support his recovery from this tumor.

\section{References}

[1] P. Dulguerov, A. S. Allal, and T. C. Calcaterra, "Esthesioneuroblastoma: a meta-analysis and review," The Lancet Oncology, vol. 2, no. 11, pp. 683-690, 2001.

[2] D. Jethanamest, L. G. Morris, A. G. Sikora, and D. I. Kutler, "Esthesioneuroblastoma: a population-based analysis of survival and prognostic factors," JAMA Otolaryngology-Head \& Neck Surgery, vol. 133, no. 3, pp. 276-280, 2007.

[3] D. M. Mintzer, S. Zheng, M. Nagamine, J. Newman, and M. Benito, "Esthesioneuroblastoma (olfactory neuroblastoma) with ectopic ACTH syndrome: A multidisciplinary case presentation from the Joan Karnell Cancer Center of Pennsylvania Hospital," The Oncologist, vol. 15, no. 1, pp. 51-58, 2010.

[4] A. Morita, M. J. Ebersold, K. D. Olsen, R. L. Foote, J. E. Lewis, and L. M. Quast, "Esthesioneuroblastoma: prognosis and management," Neurosurgery, vol. 32, no. 5, pp. 706-714, 1993.

[5] B. Wiedenmann, W. W. Franke, C. Kuhn, R. Moll, and V. E. Gould, "Synaptophysin: a marker protein for neuroendocrine cells and neoplasms," Proceedings of the National Acadamy of Sciences of the United States of America, vol. 83, no. 10, pp. 35003504, 1986.

[6] L. A. Cecenarro, E. T. Rodrigo Fantón, P. Estario et al., "An infrequent presentation of esthesioneuroblastoma with ectopic ACTH syndrome," Revista argentina de endocrinología y metabolismo, vol. 51, no. 4, pp. 192-196, 2014.

[7] I. Hodish, T. J. Giordano, M. N. Starkman, and D. E. Schteingart, "Location of ectopic adrenocortical hormone-secreting tumors causing Cushing's syndrome in the paranasal sinuses," Head \& Neck, vol. 31, no. 5, pp. 699-706, 2009.

[8] B. M. Biller, A. B. Grossman, P. M. Stewart, S. Melmed, X. Bertagna, J. Bertherat et al., "Treatment of adrenocorticotropindependent Cushing's syndrome: a consensus statement," The Journal of Clinical Endocrinology \& Metabolism, vol. 93, no. 7, pp. 2454-2462, 2008.

[9] E. Charmandari, N. C. Nicolaides, and G. P. Chrousos, "Adrenal insufficiency," The Lancet, vol. 383, pp. 2152-2167, 2014. 


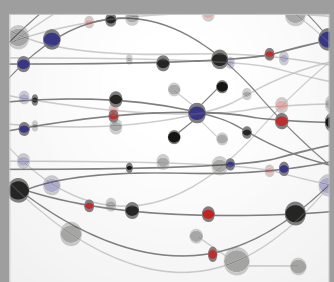

The Scientific World Journal
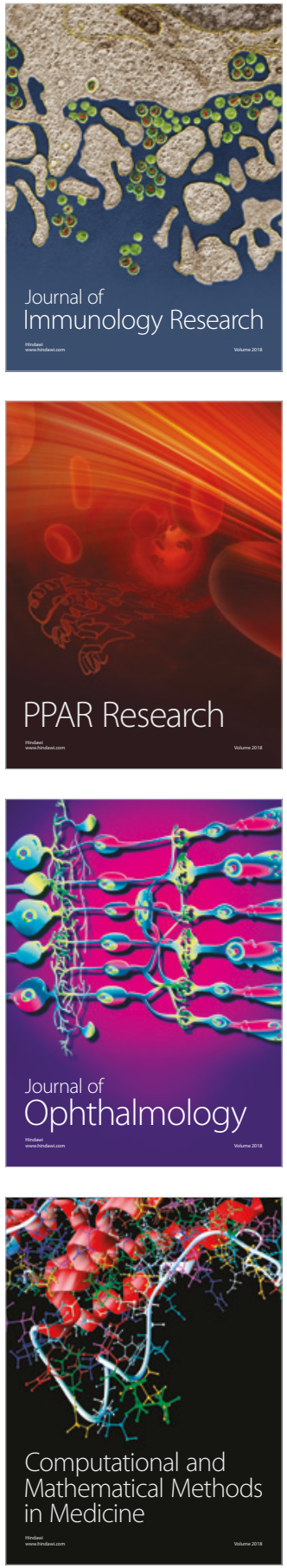

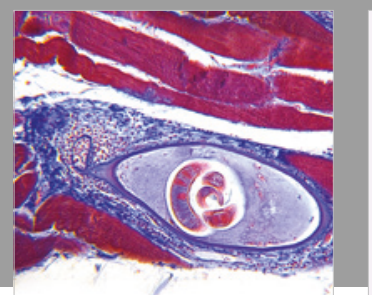

Gastroenterology Research and Practice

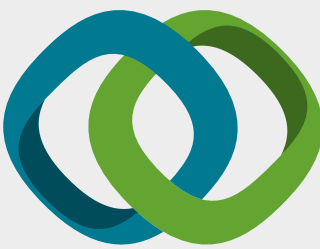

\section{Hindawi}

Submit your manuscripts at

www.hindawi.com
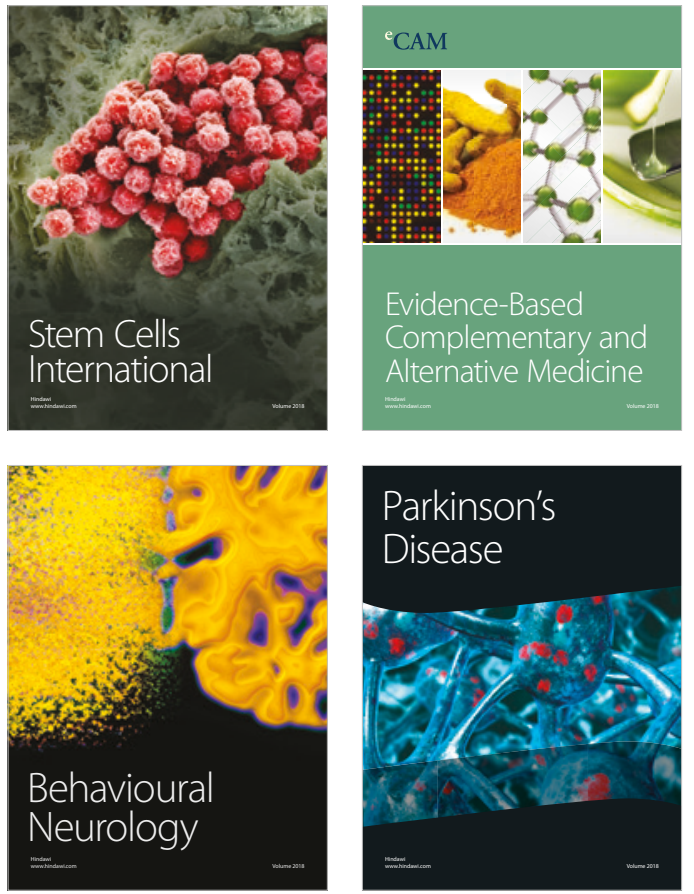

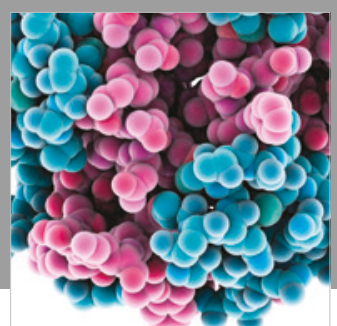

ournal of

Diabetes Research

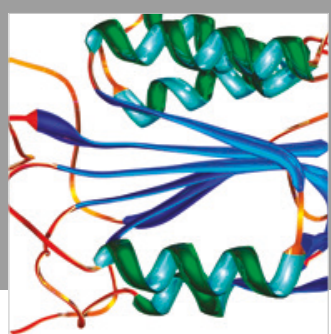

Disease Markers
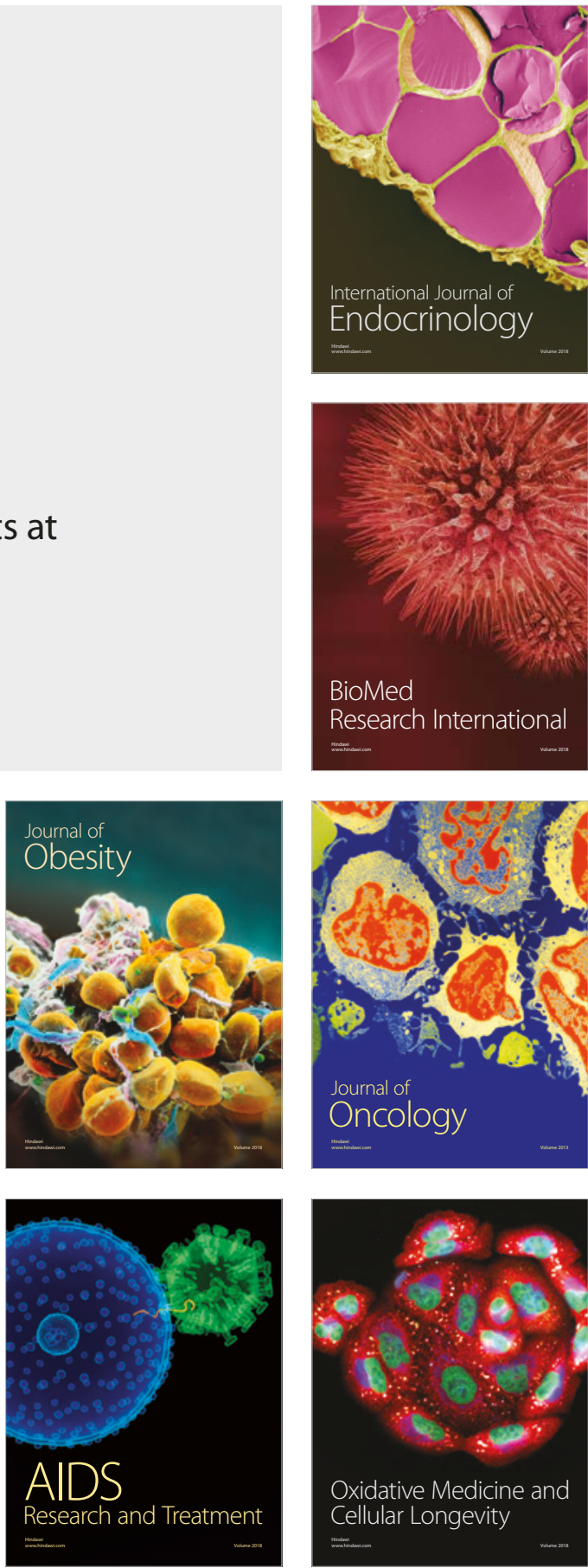